\title{
Non-oxidative conversion of methane into higher hydrocarbons over Mo/MCM-22 catalyst
}

\author{
SOURABH MISHRA, SONIT BALYAN, KAMAL K PANT* and M ALI HAIDER \\ Department of Chemical Engineering, Indian Institute of Technology, Delhi 110 016, India \\ E-mail: kkpant@chemical.iitd.ac.in
}

MS received 27 May 2017; revised 3 August 2017; accepted 17 August 2017; published online 27 September 2017

\begin{abstract}
Molybdenum impregnated zeolite catalyst has been well-known for methane conversion into higher hydrocarbons under non-oxidative condition. HZSM-5 \& HMCM-22 zeolites are the effective supports for this purpose. However, the catalytic performance of HMCM-22 supported molybdenum catalyst is considered suitable than that for HZSM-5 catalyst with high aromatic selectivity due to unique pore structure and framework of MCM-22 zeolite support. Effect of Mo loading over MCM-22 zeolite has been studied for the activity test and observed that $5 \mathrm{wt} \%$ metal content over the support (MCM-22) is optimum for the proper tuning of acidic $\&$ metallic sites of the catalyst. Effect of silica/alumina ratio (SAR, molar) of MCM-22 zeolite has also been studied and observed that lower SAR (30) is suitable $\left(\mathrm{C}_{6} \mathrm{H}_{6}\right.$ selectivity, $\left.37 \%\right)$ comparatively to higher SAR (55) $\left(\mathrm{C}_{6} \mathrm{H}_{6}\right.$ selectivity, 18\%). Lower GHSV $(720 \mathrm{~mL} / \mathrm{g} . \mathrm{h})$ is effective for higher hydrocarbon production compared to higher GHSV (1200 mL/g.h) due to low residence time. Mo/MCM-22 catalysts with different Mo loading were characterized by BET surface area, XRD, Raman spectroscopy and $\mathrm{NH}_{3}$-TPD analysis. Unique pore systems [10 \& 12 membered ring (MR)] and framework of MCM-22 zeolite support are the key factors for effective methane conversion to value added chemicals when loaded with molybdenum.
\end{abstract}

Keywords. HZSM-5; HMCM-22; SAR (silica alumina ratio, molar); GHSV (mL/g.h).

\section{Introduction}

Discovery of shale gas, a type of natural gas, has attracted people for its effective utilization and will become a promising source of energy for the next two decades. However utilization of the resources of natural gas is bounded by its availability at remote locations and the gas transportation cost. ${ }^{1}$ Methane, major content of natural gas (more than $80 \%$ ) can be potentially used as a raw material for the production of higher hydrocarbons and valuable chemicals and thus conversion of methane (natural gas) into transportable chemicals can solve the utilization problems. Although reactions with methane require $\mathrm{C}-\mathrm{H}$ bond activation which proceeds with a relatively high activation energy barrier $\left(E_{a}=435 \mathrm{KJ} / \mathrm{mole}\right)$ in the vapor phase. Therefore, methane tends to remain stable and it's conversion to commodity chemicals remains thermodynamically challenging. ${ }^{2,3}$ Basically two major paths are available for methane conversion reaction, direct $\&$ indirect process in heterogeneous catalysis. Conversion of methane

\footnotetext{
*For correspondence
}

via synthesis gas is an indirect method and can be used to produce methanol or higher hydrocarbons. Thus the indirect rout goes with the formation of an intermediate (Syn-gas, $\mathrm{CO}+\mathrm{H}_{2}$ ) formation via steam reforming, dry reforming or partial oxidation of methane which followed by a Fisher-Tropsch process gives value added chemicals. Nevertheless, some factors such as catalyst deactivation and requirement to obtain $1: 1$ ratio $(\mathrm{mol} / \mathrm{mol})$ of the syn-gas are the basic problems in the commercialization of this rout, thus anticipates large capital expenditures. Whereas the direct conversion of natural gas into higher hydrocarbon has an advantage over indirect processes as it eliminates the intermediate step of forming syngas. ${ }^{4}$ However, due to high bond energy of methane molecule $(435 \mathrm{~kJ} / \mathrm{mole})$, the transformation of methane into higher hydrocarbons is thermodynamically less favourable and requires temperatures above $1200^{\circ} \mathrm{C}$ to obtain an industrially practical level conversion. Some processes such as direct catalytic conversion of methane to value added compounds are available in which methane dehydroaromatization (MDA) is an excellent approach to convert methane 
directly into aromatic compounds and thus can effectively exploit the natural gas. Firstly, in 1993, Wang et al., ${ }^{5}$ reported methane conversion to aromatics such as benzene and naphthalene on a HZSM-5 supported molybdenum (Mo) catalyst under non-oxidative conditions at $700^{\circ} \mathrm{C}$ temperature and atmospheric pressure. Since at that time, several studies have been done to investigate suitable catalyst for this purpose, and it was observed that Mo/ZSM-5 catalyst was the most effective among all the reported catalysts. ${ }^{6,7}$ However in addition to Mo/ZSM- 5 catalyst, $\mathrm{Mo} / \mathrm{MCM}-22$ catalyst is reported for better catalytic performance with higher aromatic selectivity as well as effective tolerance to coke formation, compared to Mo/HZSM-5 catalyst under similar conditions. ${ }^{8}$ MCM-22 zeolite, with high thermal stability and a high surface area was first synthesized by Mobil Oil Corporation. It consists of two independent channel systems (multidimensional), in which one system is $2 \mathrm{D}$ 10-MR sinusoidal (inter-layer) channel systems, while the second channel systems contain 12-MR super-cages with inner space of $0.71 \times 0.71 \times 1.82 \mathrm{~nm} .{ }^{9}$ Thus, the unique pore structure and framework of MCM-22 zeolite makes it effective for direct methane conversion into higher hydrocarbons when loaded with molybdenum. Although due to complex synthesis and less commercial availability, MCM-22 is less preferred than ZSM-5 for the reaction under non-oxidative condition. In our earlier work, we have investigated the effect of promoters such as Ga and $\mathrm{Zn}$ over Mo/HZSM-5 catalyst for stability and selectivity for methanol assisted methane conversion into higher hydrocarbons. ${ }^{10,11}$ The fundamental study gives the schematic insights of how methanol assists in $\mathrm{H}-\mathrm{H}_{3} \mathrm{C}$ bond activation under thermo-neutral temperature for forming of carbocation which are primary species for $\mathrm{C}-\mathrm{C}$ coupling for aromatic formation. Catalyst formulation which consists of molybdenum supported zeolites, significantly affects the reaction on varying Mo loading and acidity of zeolite support. ${ }^{12,13} \mathrm{In}$ the present work we have studied the Mo/MCM-22 catalyst in detail with different molybdenum loading and silica alumina ratio (high and low) of MCM-22 varying acidity, which play a crucial role in upgrading the methane conversion and product selectivity.

\section{Experimental}

\subsection{Catalyst preparation}

All the chemicals used for this study were of high purity $(>99.9 \%)$. Ammonium heptamolybdate $\left[\left(\mathrm{NH}_{4}\right) 6 \mathrm{Mo}_{7} \mathrm{O}_{24}\right.$. $\mathrm{H}_{2} \mathrm{O}$ )], as source of molybdenum (Mo) was purchased by Merck, Germany. HMCM-22 was supplied by Sud-Chemie, with a $\mathrm{SiO}_{2} / \mathrm{Al}_{2} \mathrm{O}_{3}$ ratio (molar) of $55 \& 30$. Mo loading (2, 5 and 10 wt \%) over HMCM-22 zeolite was done by a well-known wet impregnation method. ${ }^{12}$ Aqueous solution of ammonium heptamolybdate was added drop wise to aqueous slurry of HMCM-22 zeolite and stirred well. After impregnation, water was removed by rotatory evaporator and the catalyst was dried at $110^{\circ} \mathrm{C}$ temperature overnight and then calcined in air at $550^{\circ} \mathrm{C}$ for $5 \mathrm{~h}$.

\subsection{Catalyst characterization}

Specific surface area, pore volume and adsorption-desorption isotherms for the calcined catalysts were determined using Micromeritics ASAP 2010 apparatus at liquid nitrogen temperature. Nitrogen $\left(\mathrm{N}_{2}\right)$ was the adsorbate gas with a cross sectional area of $0.162 \mathrm{~nm}^{2}$ of $\mathrm{N}_{2}$ molecule. Surface area and pore volume of the catalysts were measured with the BET method.

XRD pattern of the calcined catalysts were analysed using a Phillips X Pert Diffractometer PW 1390 at $40 \mathrm{kV}$ and 30 $\mathrm{mA}$ on $\mathrm{Cu} \mathrm{K} \alpha$ radiation (1.54 $\AA$ ). The diffractograms were collected at $2 \Theta$ between $5^{\circ}$ and $40^{\circ}$.

Raman analysis was done with a Renishaw inVia Raman Microscope spectrometer equipped with a laser beam emitting at $532 \mathrm{~nm}$. The photons scattered by sample were dispersed by an 1800 lines/mm grating monochromator and simultaneously collected on a CCD camera.

$\mathrm{NH}_{3}$-TPD analysis was performed on Micromeritics, ChemiSorb 2720 set-up equipped with a thermal conductivity detector. A certain amount $(0.15 \mathrm{~g})$ of calcined catalyst was first degassed at $200^{\circ} \mathrm{C}$ temperature in an inert atmosphere (Ar) to remove impurities and then treated with ammonia-helium mixture (5 wt $\%$ ammonia balanced helium) for complete saturation for 45 mins. After physisorbed ammonia was removed by inert helium, TPD was carried out at a heating ramp of $10^{\circ} \mathrm{C}$ up to $800^{\circ} \mathrm{C}$. Total desorbed $\mathrm{NH}_{3}$ was analysed from the integrated peak area of the TPD profiles relative to the calibration curves.

Amount of coke deposited on the catalysts during the reaction was analysed by oxidation in air by thermogravimetric analyser (TGA, Q600). In an alumina pan, $12 \mathrm{mg}$ of spent catalyst was loaded and heated to $700^{\circ} \mathrm{C}$ at the rate of $10^{\circ} \mathrm{C}$ $\min ^{-1}$. The mass change of the catalyst with temperature was recorded and the amount of coke formed over the catalyst was calculated.

\subsection{Catalyst evaluation}

Activity test of the catalyst was performed in a continuous fixed-bed tubular reactor (500 mm length \& $15 \mathrm{~mm}$ ID) at $700^{\circ} \mathrm{C}$ and atmospheric pressure with $720 \mathrm{~mL} / \mathrm{g} . \mathrm{hr}$ GHSV. Calcined catalyst was first treated with a mixture of $\mathrm{H}_{2}, \mathrm{CH}_{4}$ \& $\mathrm{N}_{2}$ (3:1:1) for 4 to $5 \mathrm{~h}$ to activate the catalyst where $\mathrm{N}_{2}$ was used as inert gas. After catalyst activation, the reaction was carried out with a mixture of $\mathrm{CH}_{4}$ and $\mathrm{N}_{2}$ as inert. With $\mathrm{N}_{2}$ as an internal standard, methane conversion and product selectivity were calculated by using gas chromatographs 
Table 1. Physical properties of calcined catalysts.

\begin{tabular}{lcc}
\hline Catalysts & BET surface area $\left(\mathrm{m}^{2} / \mathrm{g}\right)$ & Micropore \\
\hline HMCM-22 (SAR-30) & 438 & 0.19 \\
5 wt\% Mo/HMCM-22 (SAR-30) & 398 & 0.15 \\
HMCM-22 (SAR-55) & 387 & 0.13 \\
2 wt\% Mo/HMCM-22 (SAR-55) & 342 & 0.11 \\
5 wt\% Mo/HMCM-22 (SAR-55) & 309 & 0.09 \\
10wt\% Mo/HMCM-22 (SAR-55) & 281 & 0.06 \\
\hline
\end{tabular}
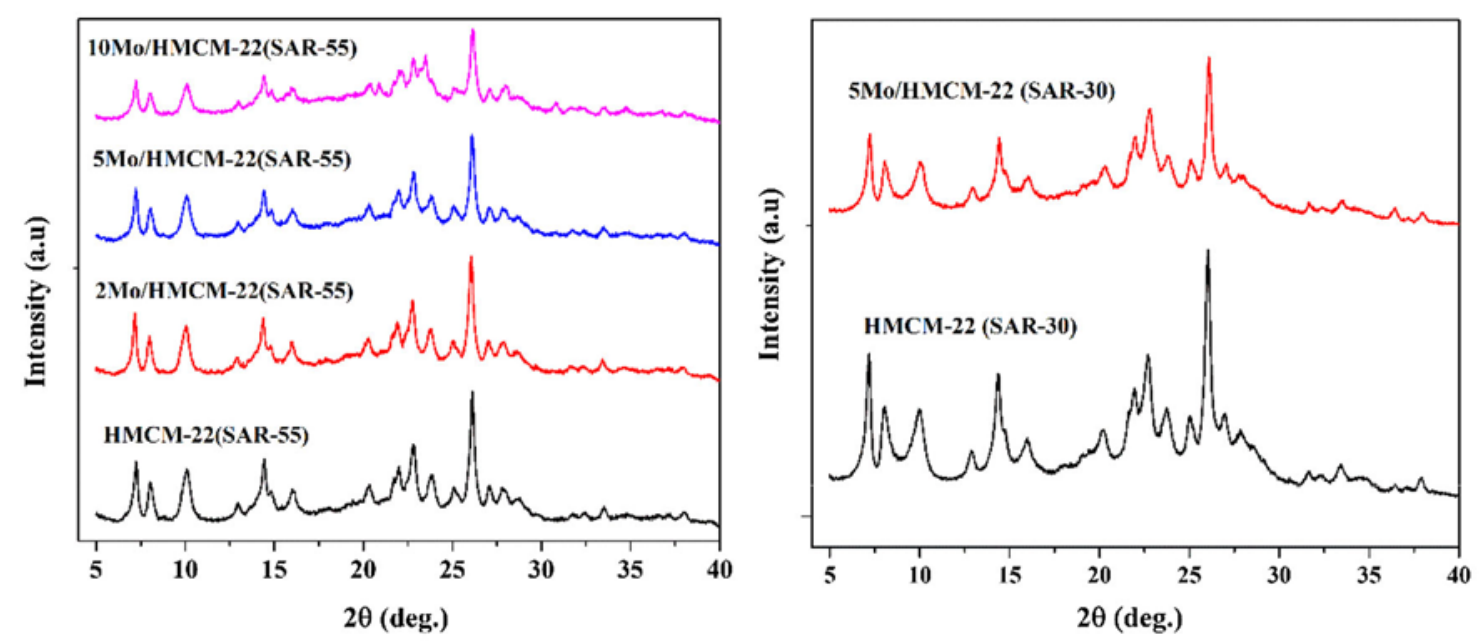

Figure 1. XRD pattern of calcined catalysts.

(GC). Thermal conductivity detector (TCD) \& Flame ionization detector (FID) connected with GC is used for methane conversion \& product selectivity analysis. To validate the data some runs were carried out in triplicate and mass balance for all the runs was measured. Runs with a mass balance less than $75 \%$ were discarded.

\section{Results and Discussion}

\subsection{Characterization of calcined catalyst by BET,} $X R D$, Raman spectroscopy and $\mathrm{NH}_{3} \mathrm{TPD}$ analysis

The specific surface area and pore volume of the calcined catalysts were measured by BET method using nitrogen adsorption at $-196^{\circ} \mathrm{C}$. BET surface area and pore volume of HMCM-22 and molybdenum loaded HMCM-22, prepared by wet impregnation method are given in Table 1. It was observed that surface area of the catalyst decreased on metal loading. Surface area and pore volume slightly decreases due to the partial incorporation of Mo metal into HMCM-22 zeolite channels $\&$ migration of Mo species inside the pores of the zeolite support during the impregnation of Mo over HMCM-22 zeolite support. Surface area and pore volume observed for calcined catalysts and its variation on metal loading are comparable with the literature. ${ }^{14}$

Figure 1 shows the XRD pattern of the calcined catalysts with different Mo loading over HMCM-22 zeolite and it can be inferred that there is not much change in the XRD pattern of the HMCM-22 zeolite after Mo loading which is comparable with the literature ${ }^{14}$ also, thus Mo does not affect the channel framework \& crystallinity. Due to a lower concentration of Mo species and its migration to the zeolite pores, there are no peaks observed for $\mathrm{MoO}_{\mathrm{x}}$ species in the XRD pattern. However, the intensity of the peaks of HMCM-22 zeolite slightly decreases on metal loading. Shu et al., ${ }^{15,16}$ reported that for lower Mo loading, $\mathrm{MoO}_{\mathrm{x}}$ crystallite patterns could not be identified and the crystallites of $\mathrm{MoO}_{\mathrm{x}}$ are lesser than $4 \mathrm{~nm}$ and cannot be identified by $\mathrm{XRD}$ technique as it can be clearly observed from the diffraction pattern of the fresh catalyst indicating only reflections of the HMCM-22 zeolite and it is not possible to find any molybdenum active phases of the catalyst.

Figure 2 shows Raman spectra of the calcined catalysts (2, 5, \& $10 \mathrm{wt} \% \mathrm{Mo} / \mathrm{HMCM}-22$ (SAR-55)). The bands observed at 980, 973 and $965 \mathrm{~cm}^{-1}$ correspond to the $\mathrm{MoO}_{\mathrm{x}}$ species grafted over HMCM-22 channel at $\mathrm{Al}$ sites similar to the reported literature. ${ }^{17}$ 


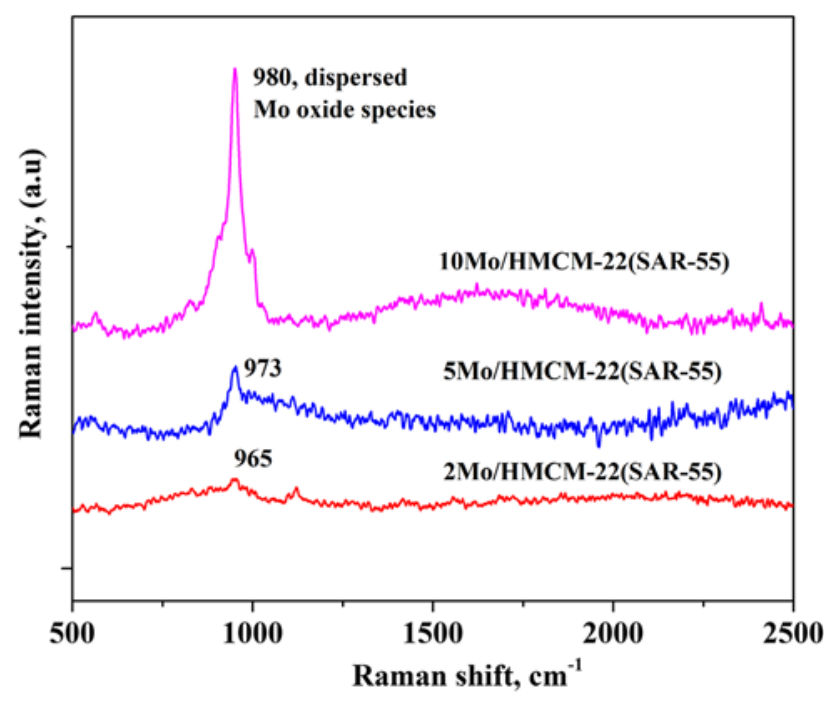

Figure 2. Raman spectra of calcined catalysts.

Thus $\mathrm{MoO}_{\mathrm{x}}$ species grafted over MCM-22 zeolite channel were observed in Raman spectra as there was no phase found for the molybdenum species in the XRD pattern even at high loading. Although for 2 and $5 \mathrm{wt} \%$ Mo loaded MCM-22 catalyst, observed band intensity is comparatively low than that for $10 \mathrm{wt} \%$ due to a lower concentration of metal.

Acidity analysis was performed by $\mathrm{NH}_{3}$-TPD measurement. There are two ammonia desorption peaks observed centering at around $260^{\circ} \mathrm{C}$ and $470^{\circ} \mathrm{C}$ during the analysis of the calcined catalysts similar to the $\mathrm{NH}_{3}$-TPD profiles of HMCM-22 and HZSM-5 zeolites reported in the literature. ${ }^{18}$ First one is for weak acid sites (low temperature) whereas the second one for strong acid sites (high temperature) of the HMCM22 supported catalyst as shown in Figure 3. Although $\mathrm{NH}_{3}$ uptake was observed high at weak acid sites comparatively to strong acids sites inferring the lower concentration of strong acid sites over the catalysts (Table 2). $\mathrm{NH}_{3}$ uptake was observed high (for both weak and strong acid sites) for HMCM-22 with SAR-30 comparatively than that for SAR-55 resulting low acidity

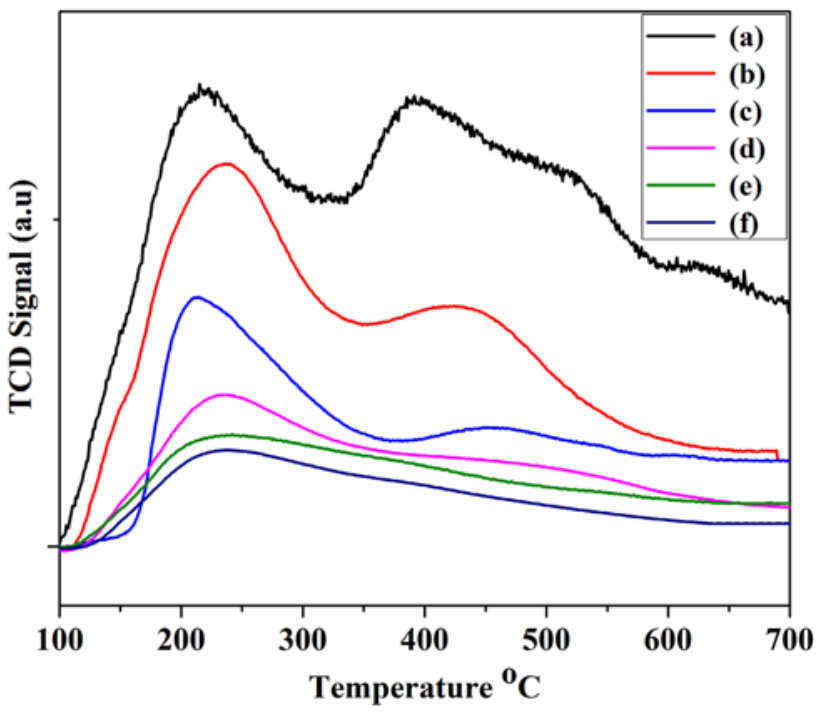

Figure 3. $\mathrm{NH}_{3}$-TPD profiles of calcined catalysts (a) HMCM-22 (SAR-30), (b) 5Mo/HMCM-22 (SAR-30) (c) HMCM-22 (SAR-55), (d) 2Mo/HMCM-22 (SAR-55), (e) 5Mo/HMCM-22 (SAR-55), (f) 10Mo/HMCM-22 (SAR-55).

for SAR-55 as shown in Table 2. From the TPD plot (Figure 3) and Table 2, it can be inferred that the acidity slightly decreases on Mo loading due to the partial exchange of acidic sites (protonic sites) of zeolite support with Mo species and the observed results for the decrease in acidity on Mo loading have been confirmed by the reported literature. ${ }^{19}$

\subsection{Activity test of calcined catalysts}

Catalytic performance of Mo/MCM-22 catalyst with different Mo loading was tested for methane activation to higher hydrocarbons under non-oxidative conditions and observed product selectivity and conversion results have been shown in Figure 4. Mo loaded MCM-22 catalysts show a bifunctional behaviour for the reaction as the molybdenum activates the $\mathrm{C}-\mathrm{H}$ bond of methane and the acidic sites of zeolite support help in $\mathrm{C}_{2}$ and higher coupling which gives higher hydrocarbons. ${ }^{12}$ Thus it is

Table 2. $\mathrm{NH}_{3}$ uptake during the TPD studies.

\begin{tabular}{lcc}
\hline Zeolite & $\begin{array}{l}\mathrm{NH}_{3} \text { uptake (mL/g STP) } \\
\text { at low temperature }\end{array}$ & $\begin{array}{l}\mathrm{NH}_{3} \text { uptake (mL/g STP) } \\
\text { at high temperature }\end{array}$ \\
\hline HMCM-22 (SAR-30) & 48.3 & 31.6 \\
5 wt\% Mo/HMCM-22 (SAR-30) & 26.8 & 17.8 \\
HMCM-22 (SAR-55) & 29.7 & 18.6 \\
2 wt\% Mo/HMCM-22 (SAR-55) & 20.4 & 11.5 \\
$5 \mathrm{wt} \%$ Mo/HMCM-22 (SAR-55) & 13.1 & 8.2 \\
10 wt\% Mo/HMCM-22 (SAR-55) & 7.3 & 3.3 \\
\hline
\end{tabular}



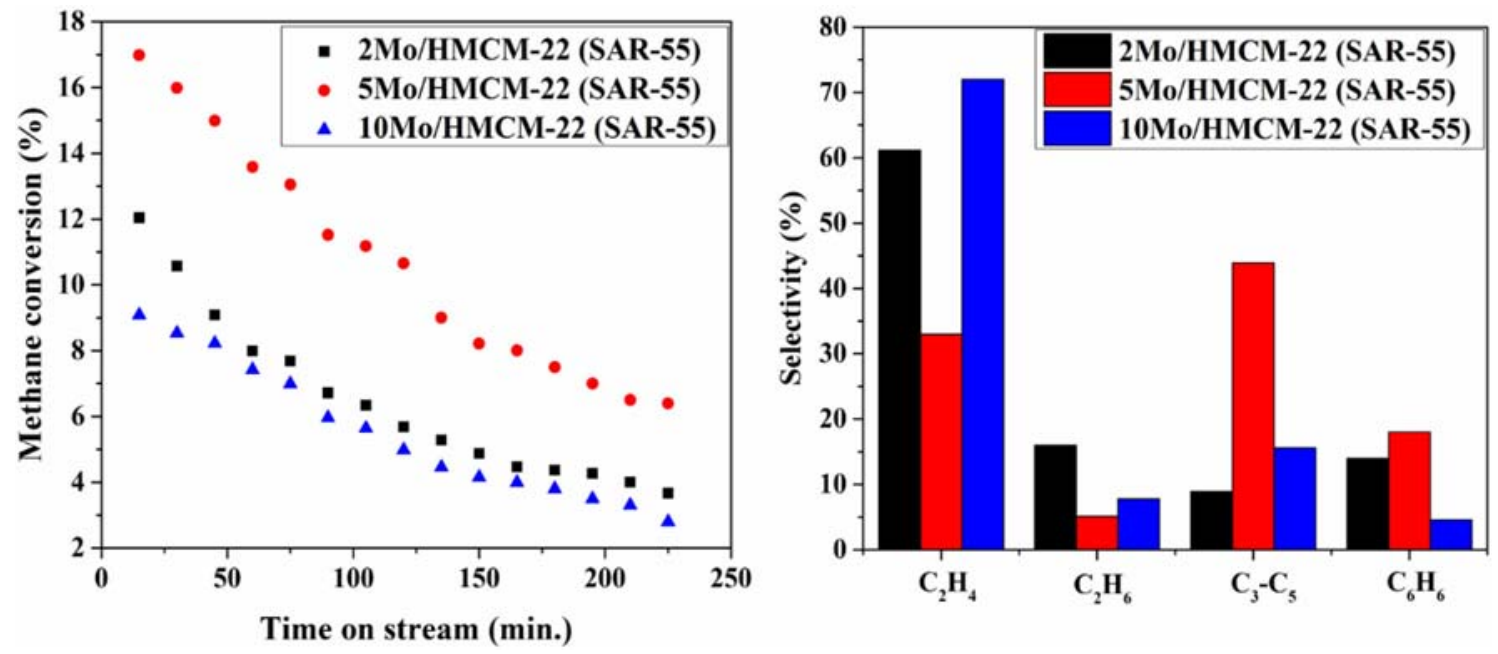

Figure 4. Conversion and product selectivity for 2, 5, and $10 \mathrm{wt} \%$ Mo loaded MCM-22 (SAR-55) catalyst.

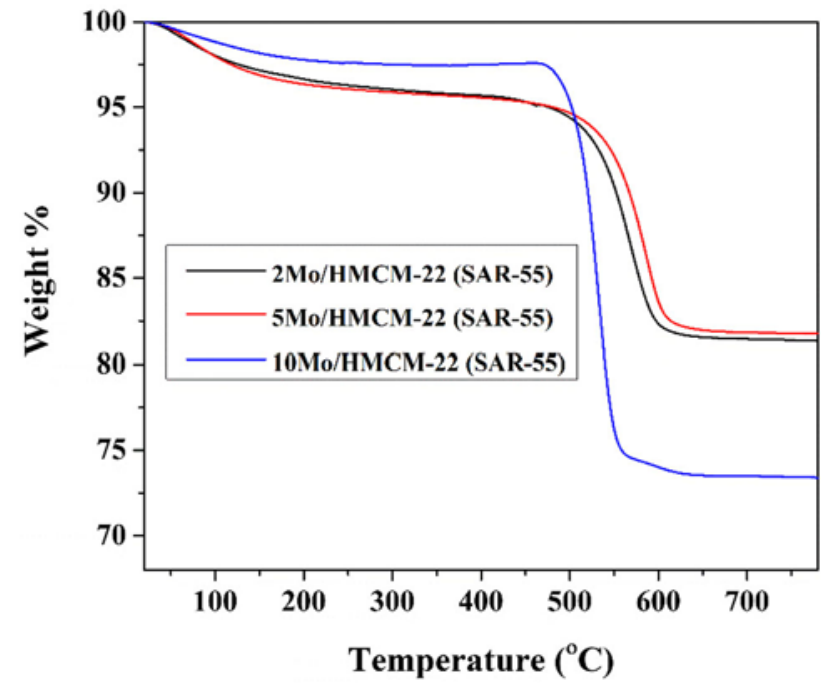

Figure 5. TGA profile for spent catalysts.

significant to maintain the trade-off between Mo loading and acidic sites of zeolite support which is crucial for effective catalyst activity. From Figure 4, it can be concluded that $5 \mathrm{wt} \%$ Mo loading is optimum for methane conversion into higher hydrocarbons at $700^{\circ} \mathrm{C}$ temperature under atmospheric pressure and $720 \mathrm{~mL} / \mathrm{g} . \mathrm{h}$ GHSV comparatively to 2 and $10 \mathrm{wt} \%$ loading. $5 \mathrm{wt} \%$ Mo loading over HMCM-22 with SAR-55 provides a proper tuning between metallic and acidic sites for higher hydrocarbon formation. 16.8\% maximum conversion has been observed for $5 \mathrm{wt} \%$ Mo loading with SAR-55 which drops to $8 \%$ conversion in $4 \mathrm{hr}$ run time and comparable with the earlier work by Bao et al., in which they reported a 12 to $7 \%$ conversion in the same duration with $6 \mathrm{wt} \%$ Mo loading having SAR65. ${ }^{13}$ Low benzene selectivity $(18 \%)$ has been observed comparatively to other hydrocarbons due to high SAR of MCM-22 resulting low acidity of the catalyst.

Coke deposition analysis for the 2, 5 and $10 \mathrm{wt} \%$ Mo loaded MCM-22 catalysts was done after the activity test by using thermogravimetric analysis. Coke formed during the reaction covers the active Mo surface and thus deactivates the active metallic sites and also blocks the pores of zeolite support. By thermogravimetric analysis, the coke deposition amount can be calculated in air environment. From Figure 5, it was observed that $10 \mathrm{wt} \%$ Mo loaded catalyst showed comparatively high weight loss due to coke formation over the catalyst, whereas for $5 \mathrm{wt} \%$ Mo loaded catalyst it was relatively low. The results observed are comparable with the reasoning given in the literature. It has been reported that if the weight percentage is greater than 5\% then Mo has a tendency to extract aluminium from the zeolite framework at elevated temperature, thus deforms the zeolite channel resulting zeolite pore blockage and reduction in pore volume which causes more carboneous species over the catalyst at high metal loading. ${ }^{20,21}$ Thus, the catalytic performance of $10 \mathrm{wt} \%$ Mo loaded MCM-22 catalyst is poor comparatively.

Additionally, SAR $\left(\mathrm{SiO}_{2} / \mathrm{Al}_{2} \mathrm{O}_{3}\right.$, molar) of MCM-22 zeolite was tested for methane conversion into higher hydrocarbons under similar experimental conditions. Commercially available HMCM-22 (SAR $30 \& 55$ ) with $5 \mathrm{wt} \%$ Mo loading have been studied. In result, the selectivity of aromatics increased to $37 \%$ in the presence of MCM-22 with SAR-30 as compared to $18 \%$ with SAR-55 as shown in Figure 6. In addition, a similar trend in methane conversion was observed for the both catalysts (Figure 6). The enhanced methane conversion and aromatic selectivity can be correlated with the acidity of both the catalysts. It has been observed that the 

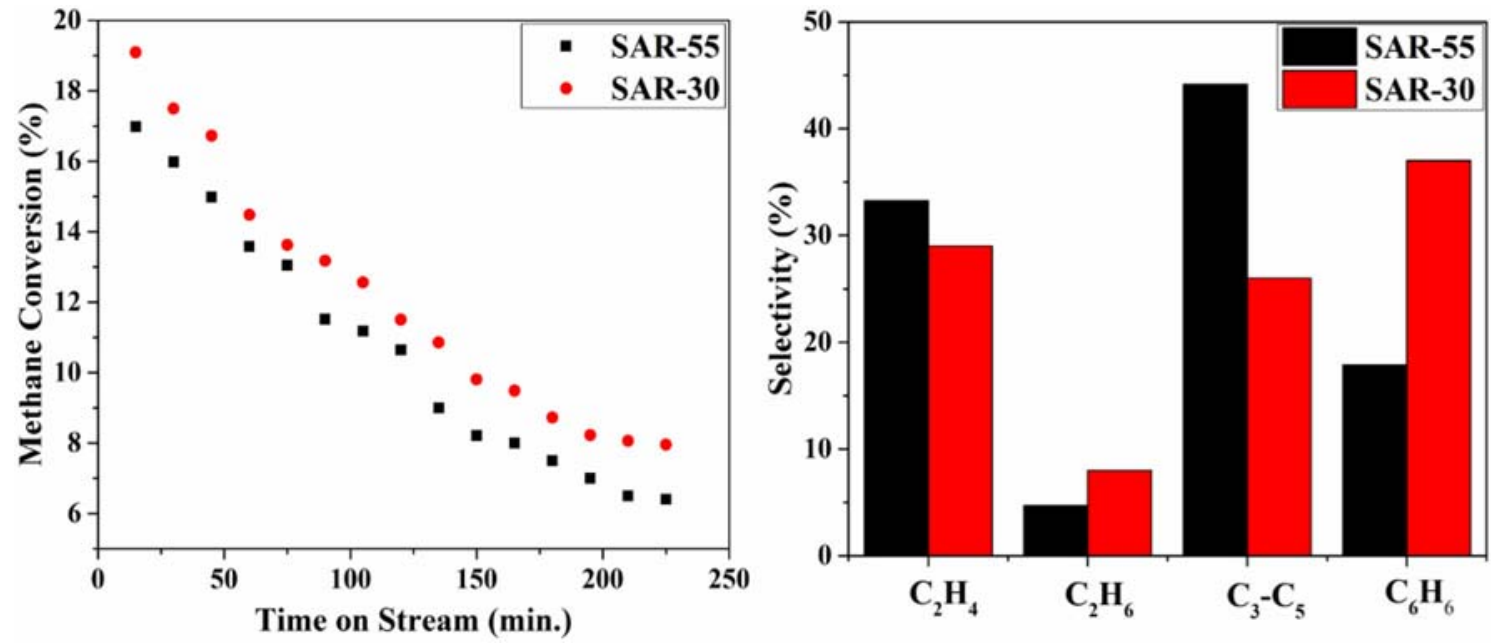

Figure 6. Conversion and product selectivity for two different SAR of 5Mo/HMCM-22 (30 \& 55) catalyst.
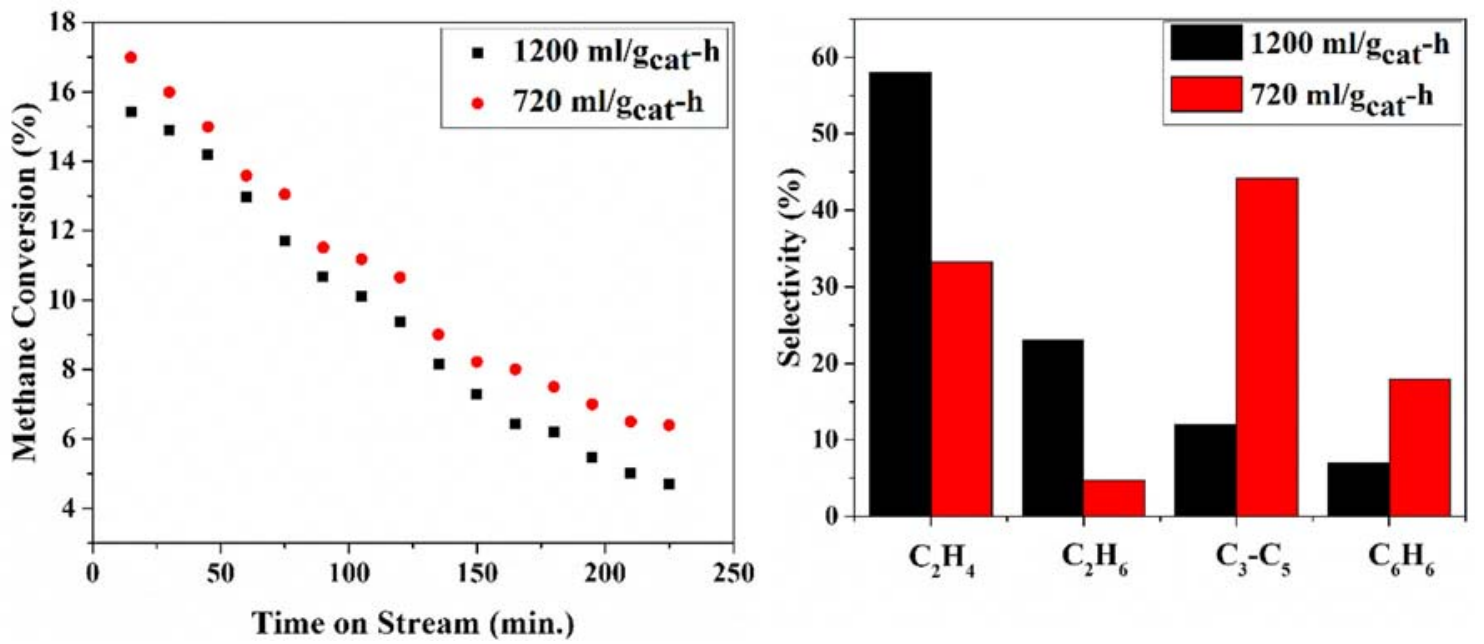

Figure 7. Effect of GHSV on conversion and product selectivity for 5Mo/HMCM-22 (SAR-55) catalyst.

lower SAR of MCM-22 zeolite enhances the concentration of acid sites as measured by $\mathrm{NH}_{3}$-TPD analysis (Table 2). Consequently, the enhanced concentration of acid sites in MCM-22 with SAR-30 (Table 2) led to the improved selectivity of higher hydrocarbon and aromatics. Obtained results for the two SAR (30 and 55) are in line with the reported study by Bao et al., ${ }^{13}$ in 2006 at different SAR.

Moreover, space velocity is a crucial parameter which affects both the conversion and aromatic selectivity. Thus, the effect of space velocity was investigated in the presence of $5 \mathrm{wt} \% \mathrm{Mo} / \mathrm{MCM}-22$ (SAR-55) catalyst at $700^{\circ} \mathrm{C}$ temperature and under atmospheric pressure. The space velocity was increased to $1200 \mathrm{~mL} / \mathrm{g}_{\text {cat }}$.h from initial value of $720 \mathrm{~mL} / \mathrm{g}_{\text {cat }}$.h. It was observed that increase in GHSV decreases desired product $\left(\mathrm{C}_{6} \mathrm{H}_{6}\right)$ selectivity as shown in Figure 7. One possible reason could be low residence time with higher GHSV. In contrast, ethylene selectivity increased with higher GHSV as compared to lower GHSV, possibly the residence time for high GHSV was less resulting into the insufficient growth of carbon chain. Similar observations have been reported by Pant $e t a l$., on space velocity effect for the same process. $^{12}$

\section{Conclusion}

Characterization and catalytic performance of Mo loaded MCM-22 catalyst has been investigated for methane conversion into higher hydrocarbons under nonoxidative conditions. HMCM-22 zeolite support due to its unique framework \& pore structure presents higher catalytic activity with high product selectivity. Catalyst parameters such as $5 \mathrm{wt} \%$ Mo loading over MCM-22 
support and lower SAR (30) of the support are the effective factors for the activity test. In addition, lower space velocity ( $720 \mathrm{~mL} / \mathrm{g}$.h) gives high selectivity for benzene comparatively to higher space velocity $(1200 \mathrm{~mL} / \mathrm{g} . \mathrm{h})$. It can be concluded that highly dispersed $\mathrm{MoO}_{\mathrm{x}}$ species over MCM-22 zeolite channel, confirmed by XRD and BET analysis, and pore structure of MCM-22 zeolite are the key factors for methane conversion into higher hydrocarbons.

\section{Acknowledgements}

Authors are thankful to Gas Authority of India Limited (GAIL, India) for providing financial support for completing this research.

\section{References}

1. Crabtree R H 1995 Aspects of Methane Chemistry Chem. Rev. 95987

2. McFarland E 2012 Unconventional Chemistry for Unconventional Natural Gas Science 338340

3. Holmen A 2009 Direct conversion of methane to fuels and chemicals Catal. Today 1422

4. Lunsford J H 2000 Catalytic conversion of methane to more useful chemicals and fuels: a challenge for the $21 \mathrm{st}$ century Catal. Today 63165

5. Linsheng W, Longxiang T and Maosong X 1993 Dehydrogenation and aromatization of methane under non oxidizing conditions Catal. Lett. 2135

6. Xu Y, Liu S and Guo X L 1994 Methane activation without using oxidants over Mo/HZSM-5 zeolite catalysts Catal. Lett. 30135

7. Zhang C, Li S and Yuan Y 1998 Aromatization of methane in the absence of oxygen over Mo-based catalysts supported on different types of zeolites Catal. Lett. 56207

8. Shu Y and Ichikawa M 2001 Catalytic dehydrocondensation of methane towards benzene and naphthalene on transition metal supported zeolite catalysts: Templating role of zeolite micropores and characterization of active metallic sites Catal. Today $\mathbf{7 1} 55$
9. Corma A, Corell C and Pérez-Pariente J 1995 Synthesis and characterization of the MCM-22 zeolite Zeolites 152

10. Majhi S, Dalai A K and Pant K K 2015 Methanol assisted methane conversion for higher hydrocarbon over bifunctional Zn-modified Mo/HZSM-5 catalyst J. Mol. Catal. A Chem. 398368

11. Majhi S and Pant K K 2013 Direct conversion of methane with methanol toward higher hydrocarbon over Ga modified Mo/H-ZSM-5 catalyst J. Ind. Eng. Chem. 20 2364

12. Majhi S, Mohanty P, Wang H and Pant K K 2013 Direct conversion of natural gas to higher hydrocarbons: A review J. Energy Chem. 22543

13. Liu L, Ma D and Chen H 2006 Methane dehydroaromatization on Mo/HMCM-22 catalysts: Effect of $\mathrm{SiO}_{2} / \mathrm{Al}_{2} \mathrm{O}_{3}$ ratio of HMCM-22 zeolite supports Catal. Lett. 10825

14. Shu Y, Ma D and Xu L 2000 Methane dehydroaromatization over Mo/MCM-22 catalysts: a highly selective catalyst for the formation of benzene Catal. Lett. 7067

15. Shu Y, Ma D, Bao X and Xu Y 2000 Methane dehydro-aromatization over a Mo/ phosphoric rare earthcontaining penta-sil type zeolite in the absence of oxygen Catal. Lett. 66161

16. Xu Y, Liu W and Wong S T 1996 Dehydrogenation and aromatization of methane in the absence of oxygen on Mo/HZSM-5 catalysts before and after $\mathrm{NH}_{4} \mathrm{OH}$ extraction Catal. Lett. 40207

17. Dai Y, Jehng J, Podkolzin S G and Wachs I E 2000 Investigation of Methane Aromatization over Mo / ZSM-5 Catalysts with Operando Molecular Spectroscopy and DFT Calculations (d) (a) (b) (c) Chem. Eng. 9945

18. Lónyi F and Valyon J 2001 On the interpretation of the $\mathrm{NH}_{3}$-TPD patterns of H-ZSM-5 and H-mordenite Microporous Mesoporous Mater. 47293

19. Sobal Z, Tvar Z and Wichterlová B 2003 Acidic and catalytic properties of Mo / MCM-22 in methane aromatization: an FTIR study Appl. Catal. A-Gen. 253271

20. Liu H, Bao X and Xu Y 2006 Methane dehydroaromatization under nonoxidative conditions over Mo/HZSM-5 catalysts: Identification and preparation of the Mo active species J. Catal. 239441

21. Chen L 1995 Dehydro-oligomerization of Methane to Ethylene and Aromatics over Molybdenum/HZSM-5 Catalyst J. Catal. 157190 